\title{
A Literatura e o Ensino de Línguas Não-Maternas: Um Conflito Assumido como Harmonia
}

\author{
(Literature and Foreign Languages Learning: \\ A Conflict Assumed as Harmony)
}

\author{
Sergio Flores Pedroso \\ (Universidade Federal de Ouro Preto, ICHS)
}

\begin{abstract}
RESUMO: Através da bistória do ensino de línguas não-maternas, a relação entre essa especialidade e a literatura tem sido favorecida por uma aprovação consensual cuja pertinência é questionada aqui. Tal aprovação se apresenta mais fincada no imaginário e na tradição do que em contribuições que a literatura realmente possa trazer para essa especialidade. Isso, considerando as prioridades a partir das quais as diversas teorias hoje atuantes no ensino de línguas não-maternas organizam o trabalho didático. Este trabalbo discute a legitimação do funcionamento do literário nesse tipo de ensino porque considera que os próprios conceitos genéricos tradicionais de literatura com que ainda se opera não são consistentes com o que exige a prática pedagógica.
\end{abstract}

PalavRas-chave: Lingǘstica aplicada; Análise do discurso; Ensino de línguas estrangeiras; Literatura.

ABSTRACT: Throughout the history of foreign language teaching, the relationship between literature and foreign language teaching has been assumed as pertinent. This paper questions that assumption and explains its consensual bases as supported more by the imagination and by the tradition than by the contributions that literature can bring to foreign language teaching. Considering the priorities at the foundations of the several theories that organize the didactic work, the own generic concepts of literature with which those theories work are not consistent with the pedagogic practice needs. This paper discusses a way of approach to literature having in view to meet those needs. KEY-WORDS: Applied linguistics; Discourse analysis; Foreign languages teaching; Literature. 


\section{Introdução}

Chama muito a atenção que, apesar da distância cronológica, a rejeição parcial ou total às propostas do método gramática-tradução está na base das diversas teorias cuja utilidade prática já se esgotou ou que ainda coexistem no ensino de línguas não-maternas ${ }^{1}$ (LNM). Tais atitudes críticas são atinentes principalmente aos dois focos do trabalho didático que esse método privilegiava e que lhe mereceram o nome: a gramática e a tradução.

O método gramática-tradução resultou da coerência entre uma prática pedagógica personalizada e as necessidades práticas da aprendizagem das línguas conhecidas como clássicas: o latim e o grego. A leitura e a escrita, nessa ordem de prioridades, trabalhavam-se principalmente a partir de textos nos quais prevalecia o teológico, o litúrgico e o literário, como já era tradicional antes que esse fazer pedagógico se prolongassem no tempo, com certas adaptações, quando o ensino de LNM começou a massificar-se.

A massificação do ensino de LNM se produziu para atender necessidades da burguesia e da classe média em franco crescimento e cada vez mais atuantes na política e na economia. A burguesia e a classe média produziam e consumiam cada vez mais cultura, entendida como a arte e as letras. O domínio escrito e oral de línguas naturais contemporâneas européias como o francês, o inglês e o alemão - que eram línguas dos centros principais de produção científica e cultural - era necessário no processo de expansão e crescimento intelectual dessas classes sociais. No entanto, a coerência do método com seus objetivos iniciais estava em contradição com as novas necessidades da prática social. Tal situação prevaleceu até as primeiras décadas do século XX.

O paradoxo se encontrava, principalmente, no fato de que a oralidade continuava sendo negligenciada a favor da leitura e da escrita. As línguas

\footnotetext{
1 Com este qualificativo quero abarcar as categorias de língua estrangeira e segunda língua. Wilkins (1994: 3715) elenca vários pontos de vista para considerar ambas as partes de uma oposição cuja validade é legitimada pelo conceito de primeira língua que, por sua vez, também não é consensual enquanto denominação para a língua materna. A dicotomia língua estrangeira/segunda língua pode ser justificada, segundo Wilkins, a partir de pressupostos individuais - a diferença está dada pelas condições de aprendizagem - ou sociais, nas quais a diferença está subordinada parcialmente ao estatuto da língua na comunidade específica.
} 
naturais recebiam tratamento semelhante ao das línguas mortas. Apesar de que essas práticas eram a causa da insatisfação de pedagogos e estudantes, o tratamento da interface literatura-ensino de LNM, porém, nunca teve a mesma ou quase nenhuma ressalva quanto a continuar entre as amostras de aplicação da linguagem apresentadas em sala de aula.

A quase unanimidade de que tem usufruído o recurso à literatura no ensino é justificada por Valdes (1986: 137), a respeito do método gramática-tradução, como decorrência de que as críticas que eram feitas a essa abordagem dirigiam-se ao seu lado lingüístico, o que fez com que a literatura fosse poupada. Um comentário desse autor ganha relevo para o aspecto que aqui começa a ser tratado:

$A$ afirmação de que a literatura pode ser usada para ensinar cultura é provavelmente aceita com tanta amplidão que se transformou em clichê. (...) Simplesmente é tido como dado que a literatura é componente viável nos programas de segunda língua num nível apropriado e que uma das principais funções da literatura é servir de veículo para transmitir a cultura do povo que fala a língua em que ela está escrita ${ }^{2}(p .137)^{3}$.

Desse raciocínio parece depreender-se que juntamente com o formalismo que caracterizou o dito método, existia o interesse pela inclusão do cultural - dentro dos limites epistemológicos da época ${ }^{4}$ - entre seus objetivos colaterais. Esses limites se estenderam até bem avançadas as alternativas teóricas e práticas que foram aparecendo a ele. Nessas alternativas, em obediência a uma tradição que recua ao iluminismo (Rivière 1990: 529), a concepção elitista da cultura a associava exclusivamente à arte e ao trabalho intelectual. É interessante que tal postura continua sedimentando o uso do termo na área do ensino de LNM, apesar do enfraquecimento da prevalência da concepção erudita do termo.

\footnotetext{
2 Salvo indicação em contrário, as traduções são minhas. Os textos originais serão incluídos em notas de rodapé.

3 The statement that literature may be used to teach culture is probably so widely accepted as to be almost a clichê. (...) It is simply accepted as a given that literature is a viable component of second language programs at the appropriate level and that one of the major functions of literature is to serve as a medium to transmit the culture of the people who speak the language in which it is written.

4 Refiro-me com isso à concepção de cultura prevalecente, que privilegiava o erudito: grandes obras da literatura "universal". Nessa universalidade, prevalece ainda a restrição à Europa e América do Norte e a referência a manifestações artísticas, de que se exclui a literatura: autores de música erudita, artes plásticas, etc. Porém, desde a segunda metade do século $\mathrm{XX}$, se bem que modestamente no seu número ? mas em franco acréscimo ?, começaram a ser divulgadas representações da produção literária de países da África, Oriente Médio e Ásia.
} 
Por outro lado, após o método gramática-tradução, o recurso à literatura tem sido mais para reforçar a atividade de leitura do que como meio para acessar a aspectos da cultura-alvo. A cultura é concebida aqui como constitutiva da dimensão ideológica da linguagem ? o que faz da memória discursiva ${ }^{5}$ um aspecto configurador ? e se manifesta como comportamento e produção de conhecimento científico e artístico. Todos os aspectos constitutivos da cultura funcionam em relação dialética e têm como fundamento o histórico de condições sócio-econômicas em que se dão.

Constando de duas partes, a tradição, o formalismo e os esforços para justificar estas duas perspectivas na visualização da literatura em relação com o ensino de LNM constituem o cenário que é examinado na primeira parte desde artigo. Na segunda parte é apresentada uma proposta de equacionamento da relação literatura/ensino que se considera que supre as necessidades atuais do ensino de LNM.

Para avançar mais nas considerações esboçadas nesta introdução, torna-se necessário explicitar agora o que apresento como conceito de literatura em função da relação com a pedagogia das LNM.

\section{O que é literatura?}

O conceito por trás do termo cultura tem evoluído através do tempo, mas a concepção primordial de "arte de bem escrever" (Delas 1994: 93) continua na base de diversos enfoques do literário. Esse autor considera essa definição como inaugural dos estudos da literatura como disciplina independente. Talvez baseado em Wellek (1978: 17-18) que explica que

no século XVII apareceu o termo "belas letras". Em 1666, Charles Perrault fez a proposta ao ministro das finanças de Louis XVI, Colbert, de criar uma Academia com uma seção de belas letras que incluiria a gramática, a eloqüência e a poética (...)

Por essa época to século XVIII), o termo 'literatura' surgiu principalmente como cultura literária, erudição, ou simplesmente conhecimento das línguas clássicas ${ }^{6}$.

\footnotetext{
5 Memória discursiva é aqui considerado o conjunto de saberes herdados, adquiridos e aprendidos que se configura como norma e é recoberto pelos saberes de uma formação social dentro da qual os sentidos são construídos.

6 In the seventeenth century the term "belles letters" emerged. In 1666 Charles Perrault proposed to Colbert, the minister of finance of Louis XIV, an Academy with a section of belles letters which was to include grammar, eloquence, and poetry. (...)

By that time the term "literature" had emerge in the sense, at first, of literary culture, erudition, or simply knowledge of the classical language.
} 
Numa tentativa de organizar a didática da literatura a partir da teoria que a orienta, Delas divide os estudos literários em três períodos. O primeiro período é descrito como de tipo retórico em que o formal na prática lingüística é priorizado. O segundo período estaria marcado pela abordagem histórica do literário. Assim a história da literatura e as biografias teriam prioridade e os textos seriam usados para acessar uma época. $\mathrm{O}$ terceiro período, enfim, que obedeceria à concepção da imanência textual, estaria marcado pelo formalismo e o estruturalismo. A sua abordagem seria hermenêutica e nela o cultural encontraria espaço.

Já nos seus primórdios, o uso do termo literatura era semanticamente instável devido a sua abrangência ${ }^{7}$ conceitual. Esse seu caráter difuso tem conseguido evitar que os esforços por defini-la reduzam essa amplidão conceitual para a qual parece ter vocação. Ela chega aos nossos dias mostrando-se pertinente tanto para referir a produção escrita de qualquer disciplina quanto a produção verbal em função estética, em que a ficção e a poesia ocupam lugar privilegiado. Isso, apesar da extensão do cânone em gênero, raça, minorias, e em configurações da obra escrita - depoimento, biografia, crônica.

Barthes (apud Delas 1994: 93) dizia que literatura era simplesmente aquilo que se ensinava sob esse nome - "Literatura é o que se ensina e pronto ${ }^{8}$ ". Considero que por trás dessa aparente omissão intelectual está o fato de que a prática ultrapassa tanto a teoria que permite o conforto de o professor se julgar fazendo trabalho pedagógico com a literatura sem a necessidade de uma rigorosa descrição teórica do objeto. Sendo mais explícito, Sparshott (1978: 13) justifica que a necessidade de explicar o que é literatura resulta principalmente do fato de ter que ser ensinada:

(...) por que há teorias sobre a natureza da literatura? A tolice humana não tem explicação: tolo não é aquele que não tem boas razões para aquilo que faz, mas aquele que desconbece as melhores razões para não fazê-lo. E antes do mais, nós sabemos, sim, por que há teorias para a literatura. É porque a literatura deve ser ensinada, e deve existir uma justificativa razoável

\footnotetext{
Para uns significava erudição e cultura literária e para outros, escrita pagã. Na Idade Média chegou a significar escrita litúrgica, mas já no século XIX abarcava a produção escrita de qualquer especialidade, chegando a reduzir-se à "literatura imaginativa". (Wellek, 1978).

8 Essa frase de Roland Barthes é citada recorrentemente para fazer referência à dificuldade de definir o que é literatura. Isso porque é curioso o fato de um teórico de prestígio como ele expressar de maneira aparentemente pouco consistente a instabilidade do conceito de literatura.
} 
para ensiná-la. Toda essa necessidade de explicação é porque deve haver um problema: a prática de ensino de literatura antecedeu muito a sua justificação ${ }^{9}$.

Hirsch (1978: 34) coincide com Barthes e Sparshott (1978) quanto à base pedagógica, mas toma mais em consideração a responsabilidade do professor pela promoção humanística. Isso porque a concepção de literatura/teoria literária pressupõe uma lista de obras essenciais - o cânone:

Literatura é qualquer texto digno de ser trabalhado junto dos estudantes por professores de literatura desde que esses textos não tenham sido abordados anteriormente em outros departamentos da escola ou da universidade. Trata-se de uma definição à qual atribuo esta virtude: encoraja-nos a pensar em nossa responsabilidade pela educação bumanística e a fazermos escolhas a partir dessa responsabilidade ${ }^{10}$.

Nos comentários citados, está implícito o fato de que, quando se fala em definir literatura, o que realmente está se querendo definir é uma teoria que organize - tipologizando e, por isso, pretendendo universalizar - o tipo de produção verbal escrita de que já se tem noção e que irá justificarse no próprio processo descritivo. A base prevalecentemente estética da produção verbal, a partir de valores tidos como dados numa formação social $^{11}$, se apresenta como a definição mais genérica de literatura consensualmente aceita na área do ensino de LNM.

A projeção da literatura como "obra de arte verbal" (Todorov 1979: 53), faz com que, na relação entre a linearidade da enunciação (intradiscurso) ? em que se faz visível o recobrimento forma/sentido ? e a sua transver-

9 (...) why there are theories about the nature of literature? Human folly is no explanation: a fool is not someone who lacks good reasons for what he does, but someone who ignores better reasons for leaving it undone. And after all we do know why there are theories of literature. It is because literature must be taught, and there must be a rationale for teaching it. All that needs to be explained is why there should be a problem: why the practice of teaching literature should have grown up in advance of its rationale.

10 Literature includes any text worthy to be taught to students by teachers of literature, when these texts are not being taught to students in other departments of a school or university. That is a stipulative definition for which I claim mainly this virtue: it encourages us to think out our responsibilities in humanistic education, and make curricular choices on the basis of those responsibilities.

11 Termo apocopado para formação econômico-social. Trata-se da relação sistêmica e contraditória de um modo de produção prevalecente e sua superestrutura política e ideológica. As relações sociais, onde se dão as relações de produção, fazem parte da estrutura do modo de produção. Os aspectos que configuram a consciência social (crenças, valores e doutrinas) e instituições (família, igreja, escola, indústria cultural), de que depende sua produção e reprodução, fazem parte da superestrutura (Poulantzas 1973). 
salidade histórico-ideológica (interdiscurso), o trabalho com a primeira ganhe destaque $^{12}$ por causa do caráter heterogêneo individual ${ }^{13}$ que a distingue $^{14}$. Isto torna possível uma produção discursiva que se distancia do comum em função da projeção verbal do imaginário do autor. Ela se dá na evocação do mundo através da criação de situações singulares ou a reprodução de situações comuns em que ressaltam os aspectos sobre os quais o autor se considera dirigindo o foco das atenções.

É evidente que os esforços por uma definição que dê conta da literatura no ensino de língua materna (LM) começam bem cedo, nos níveis mais elementares. Esse interesse pode ser explicado pela consideração da literatura como participante da configuração identitária do sujeito. A literatura contribui bastante para comunizar modos de significar/interpretar prevalecentes na formação social através do conjunto de regularidades enunciativas em diferentes áreas do saber, onde algumas dessas regularidades são prevalecentes. As formações discursivas (FD) ? esse o nome desses conjuntos? parecem estar sendo aludidas nas palavras dos autores abaixo:

O professor de francês deve, primeiramente, ensinar francês, deve habituar os seus alunos a expressar-se com adequação, corretamente, deve revelar a eles os recursos infinitos que a sua lingua materna lhes oferece. Deve também formar os seus juízos e gostos, ensiná-los a orientar bem o seu pensamento e a reconhecer o Belo sob as suas formas mutáveis. Essas duas tarefas, de fato, estão intimamente ligadas: a gramática e as letras se prestam (...) ajuda mútua. Nas grandes obras da nossa literatura, a criança francesa irá aprender o melhor da sua língua e, sem a gramática, numa bela página, as mais finas nuanças lhe escaparão ${ }^{15}$.

12 Embora haja casos de gênero em que o "como" prevalece sobre "o quê", ambos os aspectos não apresentam ocorrência hierárquica igual nos diversos gêneros e na literatura como um todo.

13 Para Adorno (1999 apud Eagleton 1997: 116) a arte é a expressão do heterogêneo individual em contraste com o princípio hegemônico e homogeneizador de identidade: a arte fala pelo diferencial e não-idêntico, promovendo as afirmações do particular sensual contra a tirania de alguma totalidade única.

14 Tal distinção - entre o literário e o não-literário - parece ser cada vez mais assumida como continuum, em termos de grau e não de tipo quando a análise se fundamenta na lingüística (Hirsch 1978; Todorov 1979; Miller 1992; Kramsch 1993).

15 Le professeur de français doit d'abord enseigner le français, habituer ses eleves à s'exprimer correctement et justement, leur révéler les ressources infinies que leur offre leur langue maternelle. Il doit aussi former leur jugement et leur goût, leur apprendre à bien conduire leur pensée et à reconnaitre le Beau sous ses formes changeantes. Ces deux tâches, en fait, son étroitement liées : la grammaire et les lettres se prêtent [...] un mutuel appui. C'est dans les grandes œuvres de notre litterature que le petit français apprendra le mieux sa langue, et, sans la grammaire, dans une belle page, les plus fines nuances lui échapperaient. L'enseignement du français ne peut donc être fondé que sur l'étude des textes. 
O ensino de francês só pode ter fundamento no estudo de textos (Clarac 1963: 13 apud Reuter 1996: 7) (Grifos meus).

Ensinam-se canções e contos principalmente a crianças nos seus primeiros anos de vida para ensiná-las a ler e para doutriná-las nos modos de pensar e sentir próprios de sua comunidade ${ }^{16}$ (Sparshott 1978) (Grifos meus).

Nessas duas citações destacam-se, no mínimo, dois aspectos da ordem do ideológico, do histórico e do cultural. Bolognini (1998: 8) chama a atenção para essa relação ? dialética porque os conceitos se recobrem teoricamente ?, a partir do pressuposto da análise do discurso ${ }^{17}$ (AD) de que o sujeito é constituído culturalmente pela linguagem.

O primeiro dos dois aspectos diz respeito à literatura na escola, que se mostra constituída sócio-historicamente. O segundo se refere a que as escolhas feitas obedecem a que a opção cultural da escola é o erudito ${ }^{18}$. A explicação para isso acha-se no fato de ela arcar com a maior responsabilidade institucional pela adequação do sujeito à sociedade. Tal adequação é feita a partir de concepções estéticas cujo fundamento se encontra em valores tradicionalmente apresentados como dados - o verdadeiro, o bem e o belo $^{19}$ - porque, ao expandir-se pelas FD que usufruem da maior parcela

16 Songs and tales are taught, in the first instance, to young children, to teach them to read and to indoctrinate them in the ways of thinking and feeling proper to their community.

17 Há, na atualidade, duas tendências na Escola Francesa da Análise do Discurso. Uma inaugural, que continua se desenvolvendo na América Latina, mas não na Europa, através de múltiplos grupos de pesquisadores em centros universitários. Sua figura principal foi o filósofo francês Michel Pêcheux. Outra corrente discursiva mais contemporânea e muito importante, cujo teórico fundador é Patrick Charaudeau, é atuante no Velho Continente e principalmente no Brasil. Ambas compartilham da concepção do discurso como efeito de sentidos, mas colocam maior ênfase em aspectos diferentes do processo da construção semântico-enunciativa da interação. A primeira atenta a conceitos seminais do materialismo histórico de Marx e Engels e a teoria do inconsciente de Lacan na explicação do processo discursivo. A segunda trabalha principalmente a partir do conceito de comunicação e de contrato, onde teorias de Wittgenstein relativas à interação enunciativa e de Benveniste, quanto à teoria da enunciação, se encontram nos seus fundamentos. Para ambas as correntes, o sentido é construído e resultante da prática social. As raízes teóricas de cada postura foram aqui reduzidas à sua essência. Uma referência maior a coerência teórica interna de cada tendência ultrapassaria os limites de uma nota de rodapé.

18 Assim classificam-se aqui conceitos, noções e produção intelectual e artística que se erguem como modelo estético e representam as preferências do grupo social no poder. Nas sociedades de origem colonial, sendo européia a remissão a esses valores e obras, implica uma violenta depreciação dos outros componentes identitários nacionais cujo lado étnico tem enorme peso e reflexos. Assim, a estética é caminho eficaz de naturalização do poder.

19 Galisson (1995: 89) sustenta que isso faz parte de uma concepção de cultura e comenta: Mas a cultura, então, é um fim em si. Conbecer-se melhor para conduzir-se melhor (cf, cultura ordinária), aceder aos 
do poder, comuniza-as. Isso é da maior importância porque são as FD que configuram a visibilidade da cultura.

A escola - ainda na pós-modernidade ${ }^{20}$ - é uma instituição cujo funcionamento representa um esforço por conservar o que Eagleton (1993: 265) chama de "organicidade da vida histórica". Trata-se da pretensa interdependência entre o cognitivo, o moral e o estético. Segundo esse autor, certas perguntas que a sociedade se faz - o que podemos saber? $\mathrm{O}$ que devemos fazer? O que nos atrai? - remetem a esses três aspectos que se agrupam em torno do conceito de estética. A pedagogia tenta responder a elas organizando o processo de ensino em função dessa concepção unitária. O paradoxal está no fato de que as práticas sociais têm ido desintegrando essa pretensa organicidade a partir da qual a pedagogia ainda teima em trabalhar.

Assim, a escola legitima concepções, firma noções e promove comportamentos que se transformam em constitutivos do sedimento da memória discursiva do sujeito. A escola está na base das identidades lingüística e nacional. A escolarização da literatura, como vimos, tem alto desempenho nesse processo e está intimamente vinculada com a inscrição - primeira e irrepetível - na linguagem letrada ${ }^{21}$.

As representações sociais de escrita, leitura e literatura são construídas através da escola e determinam qualquer aproximação de um modo diferente de enunciação que não tem como acontecer sem o esforço de adequa-

tesouros patrimoniais da literatura, das artes, e à bagagem de homem digno (cf. cultura erudita; o belo, o bem, o verdadeiro) para explorar todos os recursos de sua personalidade e pô-los a serviço do próximo, constituem as finalidades culturais de que a escola jamais tem estado isenta.

[Mais alors la culture est aussi une fin en soi. Mieux se connaître pour mieux se conduire (cf. la culture courante), accéder aux trésors patrimoniaux de la littérature, des arts, et au bagage d'honnête homme (cf. la culture savante: le beau, le bien, le vrai) pour exploiter toutes les ressources de sa personnalité et les mettre au service d'autrui, constituent les finalités culturelles dont l'école n'est jamais quitte].

20 A concepção de pós-modernidade que estará sendo usada neste trabalho baseia-se em Usher e Edwards (1994: 6-19) que a referem como sentimento de mudança em relação à modernidade a partir de adequações a novas condições sócio-históricas que implicam em reformulações conceituais e atenção a aspectos do homem e da dinâmica social cujo grau de atenção era menor ao atual ou inexistia - sujeito, heterogeneidade, discurso, identidade, texto, etc.

21 Com essa expressão faço referência à relação entre práticas sociais e práticas de leitura e escrita, que tem a escola como lugar privilegiado de acontecimento e ponto de partida (Street 1984; Rockhill 1993; Kleiman 1995). 
ção do heterogêneo ao que se apresenta como natural. A visão da literatura fora das margens conceituais que aqui foram elaboradas em função do ensino de LNM contribuiria para cristalizar o paradoxo que? aqui se considera? existe na atualidade e que grosso modo consiste em agir como se o estudante participasse do contato com o processo pedagógico em LNM em estado de virgindade lingüística. Em conseqüência disso, trata-se de repetir o processo de inscrição na LM. No que tange à literatura, dribla-se essa inconsistência trabalhando com o recorte literário, mas desconhecendo-lhe o caráter artístico que o identifica.

O que aqui está sendo proposto principalmente é que o estudante participa do processo de ensino/aprendizagem com um patrimônio identitário que em nada torna possível ele ser considerado inexperiente em qualquer prática discursiva ${ }^{22}$ básica com a LNM. Isto determina que $o$ mecanismo contrastivo, sempre funcionando num segundo plano, irá arcar com uma parcela expressiva de responsabilidade pelo processo de inscrição na nova discursividade ${ }^{23}$.

\section{O literário em LNM}

Neste título, fiz a escolha do termo "literário" e não "literatura" pois sou de parecer que, na tradição do ensino de LNM, tem-se recorrido ao texto literário - mais concretamente a recortes dele - para o trabalho com a gramática e a leitura e não visando a sistematizar elementos que identificam uma pretensa ordem da literatura - quanto a gênero, movimento, autor, tema, etc. - a partir de sua "textualidade ${ }^{24}$ ". Isto, qualquer que seja a inscrição com que se aborde o trabalho artístico com a linguagem.

$\mathrm{O}$ que parece indicar a presença de recortes de textos literários nos livros didáticos (LD) de LNM é a percepção da necessidade de considerar o

\footnotetext{
22 A AD considera uma prática discursiva a materialização do trabalho com a linguagem para produzir/interpretar sentidos através da enunciação.

23 A discursividade é um modo de trabalho com a linguagem para produzir/interpretar efeitos de sentido que apenas são possíveis fincados na história através da ideologia e configurados pelas condições de produção. Toda LNM é uma discursividade outra.

24 Sendo o texto a unidade discursiva, a textualidade é constituída pela relação do texto consigo mesmo e com a exterioridade, é o lugar do interdiscurso em conjunção com as condições peculiares de produção dos sentidos.
} 
componente cultural no ensino. Tal consideração se fundamenta na concepção de que a cultura é principalmente arte ${ }^{25}$. Assim, é estabelecida uma relação remissiva entre leitura/escrita e literatura, sendo considerada esta última a cristalização do trabalho contextual com a linguagem e formalmente modelar.

Em artigo sobre a inclusão do literário em LD de inglês e alemão, Arnold e Decognier (1998: 307) comentam:

O que surpreende, quando se trata de justificar a escolba de um trecho literário, é que o que determina a escolba é o seu conteúdo cultural explícito: a Real Força Aérea na segunda guerra mundial, a corrida ao ouro na Califórnia, o indio na sociedade americana, o povoamento dos Estados Unidos ou a guerra do Vietnam. Neles prevalece o bistórico muito frequientemente e não os implícitos culturais que permitem que o estudante compreenda o sentido do que lê. Pelo contrário, recorre-se ao conteído cultural explícito para acessar ao conbecimento do país cuja lingua é estudada: o trecho literário não é objeto primeiro de estudo, mas um pretexto ${ }^{26}$.

Os implícitos culturais não parecem predominar nas escolhas "culturais" dos LDs. Eles perdem para as referências à história. Nessa conclusão da citação acima, há um aspecto que considero importante. Ele é decorrente do fato de que geralmente o conteúdo histórico é assertivo. Ele é apresentado de tal maneira que não propicia a elaboração de questionamentos. Isto, na base do valor de verdade que historicamente foi construído em torno da letra impressa, ainda mais no formato de livro em contexto pedagógico, o que significa que os dados são veiculados para "informar", para consumo como conhecimento, apenas admitindo, em todo caso, opiniões favoráveis.

Os autores da citação referida demonstram que implicitamente detectaram o mecanismo com que funciona o "civilizatório" através de textos

\footnotetext{
25 Weinrich (1985 apud De Carlo e Acquistapace, 1997: 14) explica, relacionando a importância de uma língua à cultura enquanto arte, que no mundo helênico, não se conhecendo nenhuma grande obra cultural [dos bárbaros], (...) não bá razão para aprender suas línguas, o que justificava a necessidade de aprendizagem da língua grega.

26 Ce qui frappe lorsque l'on s'interroge sur l'intérêt des extraits choisis, c'est qu'il semble que, pour beaucoup d'entre eux, ils aient été principalement choisis pour leur contenu culturel explicite: la Royal Air Force dans la Deuxième guerre mondiale, la ruée vers l'or en Californie, les indiens dans la société americaine, le peuplement des États-Unis ou la guerre du Vietnam... Dans ces textes, très souvent, ce n'est pas l'exploration de l'implicite culturel qui permet à l'élève de comprendre le sens de ce qu'il lit, c'est au contraire le contenu culturel explicite qui est utilisé pour parfaire la connaissance du pays dont il étudie la langue : l'extrait littéraire n'est pas l'objet premier de l'étude, mais le prétexte.
} 
no ensino. Esses textos também incluem o literário quando trabalhado no sentido "informativo" do tradicional documento de civilização ou do atual "documento autêntico", cuja fonte principal é a mídia. No caso da citação em questão, atribuo o veio "civilizatório" menos à desbragada dicotomia originária povos evoluídos/povos selvagens, do que a uma dissimulação bem arquitetada do que Elias (1978: 11 apud De Carlo e Acquistapace 1997: 22) descreve como segue:

(...) O termo (civilização) resume o avanço que a sociedade ocidental dos dois ou três últimos séculos acredita ter experimentado relativamente aos séculos precedentes e às sociedades contemporâneas mais "primitivas". Através desse mesmo termo, a sociedade ocidental se esforça para caracterizar aquilo que a singulariza e de que sente orgulbo: o desenvolvimento de sua tecnologia, suas regras de vida, a evolução de seu conhecimento científico e de sua visão de mundo ${ }^{27}$. (Grifos do autor)

O ensino de LNM não tem como se preservar das relações de poder refletindo-as de uma maneira ou outra - e geralmente elas se visibilizam no tratamento do cultural -, principalmente quando se trata de línguas de antigas metrópoles coloniais ou/e de atuais centros de poder. Nesses casos, sempre cintilam marcas hegemônicas ${ }^{28}$ apesar dos esforços que objetivam adequações política afirmativas que é um dos elementos tipificadores da pós-modernidade. $\mathrm{O}$ discurso pedagógico, de que neste artigo se cobra maior efetividade em sua função de adequação-apropriação de outros discursos (Berstein 1996), desempenha papel de muita importância no deslocamento seletivo do colonial.

Nesta seção está sendo salientado o lado "civilizatório" enquanto aspecto ideológico que anula qualquer questionamento do literário no ensino de LNM. Originário das relações coloniais, o civilizatório ganha aceitação graças às derivas de justificações sublimadoras que recuam, como vimos, à cultura helênica e que retomaram fôlego na nossa área nas últimas décadas do século XVIII sob o Iluminismo ${ }^{29}$.

27 Le terme résume l'avance que la société occidentale des deux ou trois dernier siècles croit avoir prise sur les siècles précédents et sur les sociétés contemporaines plus " primitives ». C'est par ce même terme que la société occidentale tente caractériser ce qui la singularise, ce dont elle est fière : le développement de sa technique, ses règles du savoir vivre, l'évolution de sa connaissance scientifique et de sa vision du monde.

28 Philipson (1992: 47) denomina "lingüicismo" o trabalho das ideologias através das línguas em função das relações de poder. Esse seu conceito é essencialmente bem próximo daquilo que Mey (1985: 16) chamou de "manipulação lingüística".

29 De Carlo e Acquistapace (1997: 12) descrevem-no assim: A convicção de que a civilização francesa tem capacidade para representar a máxima aspiração de todos os homens recua às últimas décadas do século 
Tais derivas encontram em Diderot (1965 apud De Carlos e Acquistapace 1997: 15) um porta-voz quando sustenta ufanistamente que a língua francesa é, dentre todas as linguas, a mais bem construida, a mais exata e a mais estimada, a que menos tem conservado as negligências a que chamo balbuciação da primeira idade ${ }^{30}$.

Justificações como essa tiveram seu reflexo no fato de o francês chegar a desempenhar o papel de língua franca entre a realeza européia. Tais justificações visavam a legitimar a expansão geográfica que a língua e a cultura francesas ganhavam na Europa em decorrência do crescimento do seu poder econômico e político. Obras filosóficas, trabalhos científicos - a produção de conhecimento enfim - migravam do latim para o francês.

A produção literária francesa se investiu de prestígio e com ele ungia os seus leitores e também os que, mesmo da periferia do poder, queriam ser associados a ele. A França era considerada o maior centro de irradiação de "cultura" na Europa e a literatura era a própria essência da "cultura" e da língua (De Carlo e Acquistapace 1997: 18), o que também marcou o ensino de francês como língua estrangeira através do componente "civilizatório $^{31}$ " e influenciou profundamente o ensino de LNM em geral (cf. Howatt 1994)

Assim, a melhor maneira de ensinar língua era ensinar literatura, que ainda hoje continua sendo mostrar o literário para seu consumo como leitura. A literatura era tida como "o" acesso "à" cultura. O consenso que ganhou essa idéia se prolongou tanto no tempo que se transformou em tradição no ensino de $\mathrm{LNM}^{32}$.

\footnotetext{
XVIII. Essa certeza irá constituir um leit-motiv de todo o pensamento político do século XIX a ponto de transformar-se em fundamento ideológico e legitimação das conquistas coloniais.

[La conviction que la civilisation française est en mesure de représenter un optimum à atteindre de la part de tous les hommes remonte aux dernières decennies du XVIII siècle. Cette certitude constituera un leit-motiv de toute la pensée politique $\mathrm{d}$ XIX siècle, jusqu'à devenir un soutien idéologique et une légitimation pour la conquête coloniale].

30 (...) est, de toutes les langues, la plus chatiée, la plus exacte et la plus estimable, celle qui a retenu moins de ces négligences que j'appellerais volontiers la balbutie des premiers âges.

31 O "Curso de Língua e Civilização Francesas" de G. Mauger é um bom exemplo, muito imitado nas décadas de 50 e 60 do século passado.

32 Na formação universitária de especialistas, tradicionalmente o nome da licenciatura ou bacharelado é "Língua e literatura estrangeiras" ou "Letras". A ênfase, por razões que vêm sendo expostas aqui, sempre pende para o lado da literatura.
} 


\section{Evidências e argumentos}

O que até aqui foi exposto como indícios da prevalência de posturas tradicionais não abre espaço para questionamentos que se recusem a caracterizar esses traços como de tratamento intuitivo do literário. O caráter intuitivo da relação literatura/ensino de LNM está presente na inexistência de uma concepção de literatura vocacionada para suprir as necessidades do ensino de LNM. Nessa relação, o intercultural e o tradutório se desempenhariam como aspectos imanentes. Assim, como resposta às duas perguntas-guia de Murphy ${ }^{33}$ (1988) a que Schaëfer (2000: 37) recorre para sustentar argumentos a favor do conceito de meta no ensino de LNM, a literatura justificaria um papel que até agora tem ficado mais na dimensão das evidências.

Considero como evidências os argumentos a que se recorre para fundamentar a inclusão de recortes de literatura. Evidências não precisam ser construídas teoricamente porque são sedimentadas pela intuição. É por isso que os esforços para justificar o literário se baseiam mais nos efeitos que se espera que produzam nos estudantes do que numa elaboração teórica que promova as pré-noções ao nível de conjunto de princípios a partir dos quais o foco e tipo de exercícios seriam determinados.

As críticas feitas acima ganham sua pertinência dos argumentos mais recorrentes para favorecer atuais inclusões e intenções de trabalho com o literário. Aparentemente, também nisso prevalecem a tradição, o imaginário e o desejo ${ }^{34}$ de professores e responsáveis pedagógicos sobre as especificidades do ensino e as expectativas do público-alvo. Isso, com a ressalva do ensino instrumental. Assim, em artigos e ensaios consultados, o que ressalta entre os argumentos são os muito indiretamente mensuráveis, como vai ser ilustrado logo adiante.

Dentre esses argumentos, é preciso excluir os formalmente lingüísticos. Esses se condensam na consideração de que os textos literários são exemplos acabados de linguagem em uso (McCarthy e Carter 1994: 135), mas se

\footnotetext{
33 "O que fazer com X que não poderia ser feito de outra maneira?" e "o que fazer com X para que o percurso até o domínio da LNM seja mais curto, eficiente e não contradiga pressupostos teóricos da inscrição (aqui considerada discursiva) do pedagogo?"

34 A tradição, gerenciando o imaginário e o desejo, faz com que a literatura se situe entre os patamares superiores de conhecimentos de prestígio porque a sociedade atribui a ela, dentro da educação em geral, uma parcela significativa na transmissão do bem, do verdadeiro e do belo para apreciação e detecção do sublime enquanto valor que representa a saturação estética.
} 
distribuem por fundamentações como a de que integra as ditas habilidades lingüísticas, ensina verbos, vocabulário em geral, etc. (Ghosn 2002: 173). Os argumentos que dizem respeito ao formalmente lingüístico não são nada difíceis de serem achados na literatura especializada.

O outro tipo de argumentos a ser excluídos são os pragmaticamente instrumentais. Esses abordam o literário como monumento, como repositório de dados principalmente históricos (Gaudard 1992: 75), etnológicos (Valdes, 1986), de análise textual (McCarthy e Carter, 1994), sociolingüísticas (Amor, 1994: 10; Vincent, 1999: 150), psicológicos (Lits, 1994: 28).

Os argumentos indiretamente mensuráveis, cuja intenção é justificar os recortes literários no ensino de LNM, dão atenção aos efeitos do literário junto aos estudantes. Entre esses efeitos, apresentados como objetivos, encontram-se:

- ajudar o estudante a assumir sua identidade e suas diferenças (Amor, 1994: 24; Lits, 1994: 25.

- propiciar que os estudantes reconheçam o belo sob suas formas mudáveis (Clarac, 1963: 31).

- cultivar nos estudantes o gosto pela poesia em LM e LNM (Akyel e Yalçin, 1990: 178).

- cultivar nos estudantes o prazer de ler (Amor, 1994: 11)

- fazer os estudantes participarem das emoções geradas na memória de outras comunidades (Solomon, 1986: 39: Akyel eYalçin, 1990: 179; Kramsch, 1993: 31).

- mobilizar o estudante para sua inscrição na LNM (Tomlinson, 1986: 34; Akyel e Yalçin, 1990).

- levar o estudante a relativizar valores, noções e comportamentos que eram tidos como únicos e naturais (Lits, 1994: 25; Delas, 1994: 93: Ghosn, 2002).

Note-se que, ressalva seja feita aos argumentos primeiro e último, acima prevalecem justificações que desconsideram que o estudante iniciante de LNM comparece à sala de aula vindo (ou ainda participando) de um processo pedagógico que o constitui como sujeito letrado ${ }^{35}$ - inclusive

\footnotetext{
35 Kramsch (1998: 56) define ser letrado assim: significa (...) ser capaz de compreender e manipular os sentidos da língua escrita. Sendo social e, por isso, culturalmente constituídos, esses sentidos representam pensamentos, sentimentos e açoes.
} 
literário ${ }^{36}$. Assim, a representação escolarizada da leitura e da escrita já existe nele. Isso o transforma compulsoriamente num consumidor potencial de produção literária e familiariza-o também com o tipo de raciocínio exigido pela instituição escolar em que operar no nível meta se evidencia como principal ferramenta didática.

O primeiro e o último dos argumentos se apresentam como aqueles em que há maior sintonia com a postura que neste trabalho se defende. Deles dependem mobilizações subjetivas e produções discursivas. Elas sempre vão ser construídas através do mecanismo contrastivo em que se desempenham as memórias individual e coletiva. Isto porque o ponto de partida para o relacional é a constituição identitária do sujeito e tais memórias a integram. A consideração da subjetividade exige o cuidado de selecionar amostras na base do respeito à textualidade própria da obra diferentemente da descontextualização que prevalece ainda em função do formalismo lingüístico ou da concepção arqueológica da relação recorteleitura/cultura-história.

O fato de denominar estrangeira uma produção discursiva envolve um gesto relacional antecedido da noção de saber-se com um certo conhecimento de si e por isso considerar-se ponto de partida, lugar natural de começo. O reconhecimento dos traços identitários próprios em conseqüência da relação com o heterogêneo está na base dos efeitos ? para os quais aqui se assinala? do trabalho com a literatura no ensino de LNM através de uma abordagem em que a textualidade é privilegiada e que na segunda parte a seguir é apresentada como proposta.

\section{Literatura e tradução: a relação orgânica}

Que mediação procurar, através da qual se possa estabelecer uma relação de remissão do literário ao ensino de LNM? É esse o foco desta segunda parte. Ao concebê-la, visei a explicitar o modo como consigo perceber essa relação: funcional e constitutiva do mecanismo contrastivo que gerencia todo acesso a uma LNM. Em artigo em que discute a situação da literatura dentro do ensino de francês-LM no nível primário na França, Reuter (1996)

36 Kramsch (1993) defende também a existência de vários tipos de letramento entre os quais considera o letramento literário. 
mostra que também nessa especialidade de ensino, a literatura encontra(va)se na necessidade de uma unanimidade básica conceitual conseqüente com a pós-modernidade. Esse autor justifica assim a assimetria existente entre a abordagem da literatura e o ensino da LM:

(...) o ensino da literatura vivencia, sem dúvida, um momento bistórico quanto a sua existência. Decorrido o tempo da evidência institucional e o dos grandes questionamentos ideológicos, esse ensino é discutido simultaneamente pelas dificuldades empíricas de seu exercício e pelas profundas mudanças teóricas nas ciências humanas em geral e na didática, particularmente na didática do francê ${ }^{37}$ (p. 14).

Parece-me que se pode inferir desse comentário a enorme influência da tradição na tomada de decisões sobre o ensino. Isso é um fato e se dá apesar das injunções que resultam das mudanças de paradigma que se têm produzido na pedagogia e nas áreas que estabelecem vínculos com ela. No que diz respeito à literatura no ensino de LNM, essa tradição é o subsídio principal que justifica a presença quase obrigatória do que se apresenta como literatura nos ensinos de LM e de LNM. No meu parecer, a inclusão da literatura - através de recortes -, especialmente no ensino de LNM, obedece a razões mercadológicas ${ }^{38}$.

Nesta segunda parte, o meu esforço está dirigido a explicitar que a relação literatura/LNM que está sendo proposta não visa a ensinar uma a partir da outra. Trata-se de abordar o literário em função de acelerar e aperfeiçoar a produção discursiva. Isso, considerando a passagem necessária por ações didáticas sem as quais a consecução desse objetivo seria impossível. Elas são:

- a mobilização da subjetividade do aluno através do assunto, o gênero, o autor, a época, etc.

- a atenção a aspectos específicos do recorte da obra literária, que estão na base da construção de sentidos nessa discursividade outra,

\footnotetext{
37 (...) l'enseignement de la litterature vit sans doute un moment historique quant à son existence. Après le temps de l'évidence institutionnelle et celui des grandes mises en cause idéologiques, il est questionné conjointement par les difficultés empiriques de son exercice et par les profondes mutation théoriques aussi bien dans les sciences humaines en général que dans les didactiques et dans la didactique du français en particulier.

38 Refiro-me, com isso, a que a especialidade de formação dos atuais profissionais do ensino é Letras ou Língua e Literatura Estrangeiras, concentra a ênfase subjetiva no componente de maior prestígio, que é a literatura. O paradoxo encontra-se em que no mercado de trabalho o espaço que a eles se abre é principalmente o da pedagogia de línguas.
} 
- a explicitação de certas condições de produção que funcionaram na geração do texto,

- a ativação do mecanismo contrastivo através do qual se faz relevante a relação forma/sentido. Esse mecanismo particulariza proximidades e afastamentos da língua-cultura primeira.

O último dos quatro aspectos acima recobre cada um dos outros. Todos os quatro, em conjunto, dão sustentação à idéia de que a tradução deve ter seu desempenho realçado na abordagem que aqui está sendo proposta. Por isso, a relação tradicional do ensino de LM que se transferiu para o de LNM - recorte-leitura/comentário-cultura-história - precisa de intervenções que transformem seus pressupostos e seus efeitos. A equação acima desconsidera a textualidade de partida, sendo que ela justifica a escolha do recorte. Isso me fez pensar que se tornaria necessário reformular a idéia expressa pela seqüência anterior. Considerando outros aspectos, ela incluiria o texto de origem e a tradução. Seus elementos seriam: recorte-texto/ leitura-contraste-comentário ${ }^{39}$.

Trata-se de substituir o hermenêutico - o sentido é dado - pelo discursivo (o sentido é construído) na pedagogização do discurso literário. Isso significa reconhecer o todo da obra, enquanto referência contextual, no seu papel de configurador da produção de sentidos, que justifica os "como" e os "porquê", e de chamar a atenção para o processo tradutório como passagem necessária do exercício de produção discursiva e operar explicitamente com essa ferramenta.

Neste trabalho sustenta-se que a LM preside toda operação com o simbólico. Esse modo de considerar o desempenho da LM determina qualquer aproximação que se faça do ensino de LNM. Tal premissa é válida para o literário e se articula com um raciocínio do qual se depreende a sua premissa: a existência de uma [produção literária em] LNM pressupõe a existência de uma [literatura em] LM o que subsume a existência de uma representação do literário a partir dessa língua inaugural. A abordagem meta do literário faz parte da formação letrada do estudante, de modo que o que se impõe é o trabalho com o que é novo para ele: o interlinguocultural.

39 Este raciocínio foi construído a partir da descrição que Reuter (op. cit: 15) faz do que ele denomina bem literário: o bem literário (a literaridade) é constituído pela relação escrita-texto-comentário ele próprio integrado num campo específico e nas instituições a que assim se vincula. 
A introdução do termo acima - uma única vez aqui - deve-se a que quero frisar o fato de que considero um paradoxo tratar a relativização cultural desconsiderando formalmente que, quanto às LNM, não há separação possível entre língua e cultura quando se faz uma abordagem relacional da perspectiva discursiva. Ela implica, como sublinha Bolognini (op. cit.: 10), que não há cultura sem linguagem, e não a linguagem sem cultura. E o papel normativo da cultura, dentro desse quadro, se dá pela linguagem. Pelo discurso.

Uma parcela bem expressiva da produção teórica consultada em função deste artigo contorna o relacional das línguas. O que existe é a concepção de uma abordagem relacional das culturas, sob o nome de interculturalidade - com uma produção teórica importante -, em que se continua preservando a idéia de ser possível trabalhar relacionalmente apenas um aspecto da dialética em que se dá o linguocultural. Neste trabalho essa relação continuará sendo chamada de interculturalidade.

Dabène (1998: 398) aponta para a necessidade de privilegiar a perspectiva contrastiva na aproximação das LNM assim:

Se a LM é a base principal da atividade cognitiva (...) sobretudo a partir das representações que o sujeito se faz, é importante impulsionar as reflexões contrastivas, dentro dessa perspectiva, e articulá-las com o saber metalingüístico que os estudantes já possuem ${ }^{40}$. (Grifos meus)

Tal comentário reforça a assunção aqui defendida quanto a que a ferramenta contrastiva é o recurso de maior valimento na aproximação do literário em LNM. Aproximação essa que não tem como contornar a prevalência da interpretação para que o texto escrito passe a existir ideologicamente para 0 leitor (Brunelli, 1999: 6). Essa passagem só é possível através do mecanismo tradutório. É com essa mediação que se produz o esforço de aproximar a produção discursiva não-materna da memória lingüística e vivencial do leitor $^{41}$. Coste (1982: 30) se refere a isso como que de passagem, dizendo que (...) o estudante-leitor pode revesti-la [a obra literária] com sua própria imagem ${ }^{42}$.

\footnotetext{
40 Si les ressorts principaux de l'activité cognitive s'appuient principalement sur la langue maternelle, mais surtout, (...) sur les représentations que s'en fait le sujet, il importe dès lors de développer les reflexions contrastives dans cette perspective et de les articules sur le savoir métalinguistique déjá intériorisé par les apprenants.

41 É por isso que García Yebra (1984: 32) sustenta que o texto passa a ser algo que pertence ao tradutor e não mais é o mesmo.

42 (...) parce que l'étudiant-lecteur peut l'investir de sa propre image.
} 
Gaudard (1992: 74), porém, é mais explícito ao comentar que textos literários em LNM obrigam os leitores a atribuir (...) a espaço-texto sua cor, suas ressonâncias, sua voz, que não podem ser estranhos a suas visões, a suas palavras, a suas lembranças ${ }^{43}$.

O processo referido acima por Coste e por Gaudard respectivamente, se apresenta como injunção interpretativa da leitura. Ela ganha maior visibilidade quando se trata da literatura. Tal descrição é válida tanto para a LM quanto para a LNM. Neste último caso, esse processo se torna mais complexo porque não existe acesso direto a um recorte do real que não seja o da inscrição primeira do sujeito na linguagem. A tradução, por isso, ganha o estatuto de mediador natural para tornar compatível com a memória discursiva do sujeito-leitor uma formulação que corresponde a outra memória.

No trabalho com o texto literário, é privilegiado o trabalho lúdico com a linguagem em função de provocar e/ou explicitar emoções (Solomon, 1986) a partir de valores diferentes ou semelhantes, mas comumente equacionados de maneira desigual. Trata-se de um trabalho singular com a linguagem, com o discurso, porque para a $\mathrm{AD}$, não há como separar a construção de sentidos da produção discursiva e das condições em que ela se dá. O texto literário é uma produção discursiva em que a emergência do individual ganha a maior prevalência tanto através do formal quanto do argumentativo, podendo, assim, ser considerada como configuração experimental da linguagem, sempre entre as margens da FD, em que o discurso permite ao autor trabalhar com o simbólico.

Levando isso em consideração, um comentário como o de Todorov (1987 apud Visuvalingam, 2001: 312), no qual assume que a literatura (...) toma seus signos como empréstimo de um sistema já totalmente constituído fora dela: a linguagem ${ }^{44}$, é apenas justificada pela $\mathrm{AD}$ considerando-o um prolongamento da história da instabilidade conceitual do objeto literatura, mas não pelo fato de "esquecer" que a literatura é linguagem, é discurso, e que a materialidade do discurso constitui sujeitos que constituem outros

\footnotetext{
43 (...) à l'espace-texte sa couleur, ses résonances, sa voix, qui ne peuvent être étrangères à leurs visions, à leurs paroles, à leurs souvenirs.

44 La litterature (...) emprunte ses signes à un système déjà tout constitué en dehors d'elle : le langage.
} 
sempre que entra em movimento (Guimarães, 1989: 72). A literatura é discurso em movimento.

No processo de produção literária, o autor, que construiu sentidos dentro do próprio "efeito de texto ${ }^{45}$ " (Visuvalingam, 2001: 313), manipula-os para fazê-los significar de maneira não-idêntica nas mesmas e/ou em outras combinatórias possíveis. Esse processo ganha maior visibilidade no caso das LNM. Tal característica da literatura obriga o ensino de LM $^{46}$ a sensibilizar o estudante a respeito desse nível diferente de trabalho com a linguagem.

Cabe ao ensino de LNM aproveitar o cumprimento dessa responsabilidade da LM como propedêutica para favorecer a produção discursiva em LNM e desenvolver a sensibilidade ao discurso através do literário. Isso passa pela LM através do mecanismo tradutório. Esse processo se efetiva com tal automatismo que produz efeito de sinonímia entre ler, interpretar e traduzir.

Biguenet e Schulte (1989: ix) endossam essa visão quando consideram que Ler, em si, é traduzir. E traduzir é traduzir uma segunda vez (...) O processo de tradução abarca, na sua essência, todo o segredo da compreensão bumana do mundo $0^{47}$.

Quando se faz referência à tradução neste artigo, o que está sendo pensado é o mecanismo contrastivo que auxilia a interpretação. Tenho preferido em algumas ocasiões, por isso, referir esse mecanismo como processual e constante chamando-o de tradutório. Isso, para contornar teorizações próprias da tradução concebida como objetivo final, de cuja análise tem resultado uma multiplicidade de teorias que a particularizam como disciplina.

Algumas dessas construções teóricas, porém, se apresentam como subsídios de muita utilidade para os propósitos visados aqui porque impri-

\footnotetext{
45 Para esta autora o efeito de texto consiste na dimensão semântica interna ao texto em função dele próprio, que considero que faz parte da feição "endo" da arte e a literatura (Eagleton, 1993; Adorno, 1988).

46 Em seu artigo, Visuvalingam atribui essa responsabilidade ao ensino de LNM, o que revela que o seu arcabouço ainda está atrelado à tradição no que se refere à literatura.

47 Reading is already translation, and translation is translation for the second time (...) The process of translating comprises in its essence the whole secret of human understanding of the world.
} 
mem uma ordem ao que era concebido intuitivamente. No caso da abordagem da relação tradução/literatura que está sendo desenvolvida, uma elaboração teórica de Steiner (1978: 34-41) ganha destaque principalmente devido a que o processo é assumido como adequação. Nela, esse autor atribui o valor de "história" apenas ao componente temporal. Isso difere da concepção discursiva, mas não antagoniza com ela. $\mathrm{Na} \mathrm{AD}$, a concepção de história, também e principalmente, implica na consideração do social. Ela envolve a interação social em cuja base estão a concepção de classe e as relações de poder, além do aspecto "tempo" (Guimarães, 1989: 76).

Steiner considera implicitamente o tempo como condições de produção sem as quais a linguagem seria silêncio:

A história é um ato de fala e o tempo passado lhe serve de crivo. Vestígios como monumentos e sítios históricos, por muito concretos que eles possam ser, devem ser "lidos", quer dizer substituidos dentro de um contexto de identificação verbal antes de receber qualquer carga afetiva. De que realidade tangivel a história usufrui fora da linguagem, fora de nossa fé racional em testemunhos essencialmente lingüústicos? (O silêncio, esse, não tem história) (...) O passado juntamente com a organização semântica da lembrança desenham uma paisagem estilizada que cada cultura codifica à sua maneira ${ }^{48}$ (p. 39).

A importância que atribuo a essa observação de Steiner deve-se a seus reflexos em três aspectos que vêm sendo referidos neste trabalho:

- a concepção de cultura, que é atinente à memória discursiva em conseqüência de saberes aprendidos, adquiridos e herdados que se explicitam na ação contrastiva,

- a inscrição subjetiva na linguagem, tida aqui como objetivo de ensino, que considera que o aspecto afetivo precede o volitivo, o justifica e decorre de projeções individuais da memória discursiva e

- a assunção da literatura como produzindo os efeitos de provocar e difundir emoções (Solomon, 1986), assumidas como construções sociais decorrentes do imaginário e constitutivamente culturais, que configuram as "leituras" que o sujeito faz daquilo

\footnotetext{
48 L'histoire et un acte de parole, le temps passé y sert de crible. (...) vestiges tels que monuments et sites historiques doivent eux aussi être "lus", c'est-à-dire replacés dans un contexte d'identification verbale avant de se charger d'une présence effective. De quelle réalité tangible l'histoire jouit-elle en dehors du langage, hors de notre foi raisonnée en des témoignages essentiellement linguistiques? (Le silence, lui, n'a pas d'histoire). (...) Le passé, avec l'organisation sémantique du souvenir, dessinent un paysage stylisé que chaque culture encode à sa manière.
} 
com que se depara na prática social. O seu esforço principal se concentra na criação de uma remissão direta do heterogêneo àquilo que é próprio. Nesse processo, este último aspecto decorre da cultura primeira.

A atenção prioritária a qualquer dos aspectos acima remete aos outros dois e na base de tudo está a condição que produz esse efeito: a incrição primeira na linguagem. A presença da LM na relação com a literatura é incontornável e sua mediação, quando aproveitada, favorece a aproximação de como sentem aqueles que significam através de outra discursividade. Isso significa em grande medida que o esforço de tornar interpretável a língua-cultura estrangeira foi bem sucedido.

Revuz (1998: 224) faz referência ao fato de que esse acesso a outra discursividade parece tender mais a estabilizar-se no nível de reconhecimento e menos no nível de compartilhamento emocional. Diante de expressões e palavras próprias da língua, sabe-se a intenção e reconhece-se a carga emotiva, mas não se sente como os usuários originais.

O trabalho com a literatura se apresenta como o lugar onde um dos exercícios prioritários é explicitar o funcionamento do que trabalha oculto. A ferramenta contrastiva é responsável por isso. A relação tradução/literatura - sempre dentro do patamar de complexidade que o ensino de LNM permite - conjuga o trabalho lúdico com a linguagem através do formal com o resultado final do desempenho artístico na construção textual ${ }^{49}$. Essa relação explicita a contradição dialética entre forma e sentido no uso da linguagem e envolve a consideração de fatores históricos e sociais que o legitimam.

A literatura costuma estar presente desde as primeiras etapas da constituição subjetiva da criança através das narrativas oralizadas e as alusões a elas no livro infantil com suas imagens e suas palavras e na transmissão institucionalizada do ser, do saber e do agir considerados mais pertinentes. A literatura é um dos recursos padronizadores do parafrástico na linguagem.

\footnotetext{
49 Wiltmart (2002: 16) comenta que o trabalho de correção tradutória ou, melhor, os comentários do professor durante o processo de ajustamento de equivalências, só se transformam em conflito quando há discordâncias quanto ao léxico ou ao estilo porque é aí onde está mais exposta a inscrição do sujeito na linguagem, sendo, por isso, a corda mais sensível. Nesse caso, trata-se de uma avaliação negativa do aprendiz quanto ao modo como opera com o que para ele é natural e inquestionável.
} 
A tradução é o recurso à paráfrase num nível de complexidade com que raramente o estudante é levado a operar. Nesse nível, o seu saber discursivo de operação com a linguagem é, primeiro, estremecido - como obriga o contato com uma LNM em situação de aprendizagem - para depois ser reforçado e enriquecido pela visualização de aspectos a que antes não prestava atenção do modo como se olha o alheio.

É precisamente por isso que a conjunção literatura/tradução favorece a inscrição do sujeito-aluno numa discursividade que não lhe é materna propiciando práticas de sensibilização ao discurso, o que faz com que reflita sobre a produção discursiva diferente discriminando contrastes e empreendendo o trabalho próprio de produção de efeitos de sentido fora de recursos miméticos que outras filiações teóricas propõem como expediente quase único, em cuja base de abordagem da linguagem prevalece a forma.

\section{Considerações finais}

Um traço característico da abordagem discursiva é que opera considerando o funcionamento integrado dos aspectos que participam da produção verbal. Essa é discurso e se materializa na enunciação que é adequada por condições de produção específicas. A abordagem da relação literaturatradução-ensino de LNM feita neste artigo tentou apresentar conseqüências da consideração dessas condições e mostrar limitações didáticas que tem resultado de sua dispensa a partir das criticas ao método gramática-tradução.

O grande esforço em negar a participação da LM no processo de ensino, assim como a tradução propriamente dita, construiu um arcabouço teórico de filiações diversas através da história desta especialidade de ensino, para justificar uma recusa que aos poucos vai apresentando rachaduras nas práticas em sala de aula e nos materiais didáticos e reforçam posturas como a que aqui está terminando de ser apresentada.

O fato de considerar que a LM gerencia o processo de aprendizagem, funcionando como mecanismo contrastivo, está na base de toda a elaboração argumentativa que aqui foi feita. $\mathrm{O}$ recurso à literatura, no ensino de LNM, é um meio pretensamente expedito para fazer com que o estudante possa ser numa outra língua sem quebrar regras seguidas no seu letramento originário. Isso porque a literatura tem se desempenhado didaticamente para transmitir e firmar os padrões ideológicos e culturais predominantes 
na formação social em que está inserido através de referenciais que são apenas veiculados pelas FD. Não há como contornar o recurso à tradução nesse caminho singular que se revela de retorno. Nas LNM, o caminho do novo transforma-se em percurso de retorno do velho, mas com a vantagem de poder comparar, relativizar, de tal maneira que a possibilidade de dizer no diferente é maior e por isso a distancia entre o saber e o sentir se reduz.

Recebido em junho de 2004 Aprovado em dezembro de 2004 E-mail: serflope@terra.com.br

\section{REFERÊNCIAS BibliográfiCAS}

Adorno, T. Teoria Estética. 1988. Trad. A. Mourão. São Paulo: Martins Fontes.

Akyel, A. e Yalçin, E. 1990. Literature in the EFL class: a study of goalachievement incongruence. In: E.L.T. Journal, 44/3: 174-179.

Amor, S. 1994. Document authentique ou texte littéraire en classe de français ? In: $E L A, 93: 8-24$.

Arnold, C. e Decognier, C.I. 1996. Manuels récents d'anglais et d'allemand: quelle place pour la littérature ? In: ELA, 104: 303-314.

Berstein, B. A. 1996. Estruturação do Discurso Pedagógico - Classe, Códigos e Controle. Trad. T. T. da Silva e L. F. Gonçalves Pereira. Petrópolis: Vozes.

Biguenet, J. e Schulte, R. 1989. The Craft of Translation. Chicago: The University of Chicago Press.

Bolognini, C.Z. 1998. Relações de contato: a questão da cultura. In: Trabalhos em Lingüística Aplicada 32: 7-14.

Brunelli, E. 1999. Uma Abordagem Tradutória para a Leitura de Textos Literários em Língua Estrangeira. Dissertação. Campinas: Unicamp, IEL.

Clarac, P. 1963. L'Enseignement du Français. Paris: PUF.

Coste, D. 1982. Apprendre la langue par la littérature. In: Littérature et Classe de Langue. Paris : Hatier, LAL.

Dabène, L. 1998. Pour une contrastivité revisitée. In: ELA 111: 393-478.

De Carlo, M. e Acquistapace, S. 1997. Civilisation/culture: histoire et développement de concepts. In: ELA, 105: 9-31.

Delas, D. 1994. De la littérature à la culture ou l'inverse ? Le fait francophone. In: ELA, 93: 91-99. 
Diderot, D. 1965 (1751).. Lettre sur les Sourds et les Muets à l'Usage de Ceux qui Entendent et qui Parlent. Edição comentada por P.H. Mayer, Genebra: Droz: 546.

Eagleton, T. 1997. Ideologia. Trad. L. C. Borges e S. Vieira. São Paulo: Boitempo. . 1993. A Ideologia da Estética. Trad. M. Sá Rego Costa. Rio de Janeiro: Zahar.

Eutas, N. 1973. La Civilisation des Moeurs. Paris : Calmann-Lévy.

Fuchs, C. 1988. Paraphrases prédicatives et contraintes énonciatives. In: G.G. Bés y C. Fuchs, Lexique et Paraphrase. Lille: Presses Universitaires de Lille: 157-171.

Galisson, R. 1995. En matière de culture le ticket AC-DI a-t-il un avenir? In: ELA, 100: 79-98.

García-Yebra, V. 1984. Teoría y Práctica de la Traducción, vol. I. Madri: Gredos.

GAUDARD, F-C. 1992. Didactique des textes littéraires: quelles sorties pour une recherche des entrées ? In: ELA, 87: 64-75.

GHosn, I. K. 2002. Four good reasons to use literature in primary school ELT. In: ELT Journal, 56/2: 172-178.

Guimarães, E. 1989. Enunciação e história. In: E. Guimarães (Org.), História e Sentido na Linguagem. Campinas, SP: Pontes: 71-79.

Hirsch, E. D. 1978. What isn't literature. In: P. Hernadi (org.) What Is Literature? Indiana: Indiana University Press: 24-34.

Howatt, A.P.R. 1994. A History of English Language Teaching. Oxford: Oxford University Press.

Kleiman, A. 1995. O que é letramento?. In: A. Kleiman (Org.) Os significados do letramento: uma nova perspectiva sobre a prática social da escrita. Campinas, SP: Mercado de Letras: 7-64.

Kramsch, C. 1993. Context and Culture in Language Teaching. Oxford: Oxford University Press.

. 1998. Language and Culture. Oxford: Oxford University Press.

Lits, M. 1994. Approche Interculturelle et Identité Narrative. Em ELA, 93: 25-37.

Mccarthy, M. e Carter, R. 1994. Language as Discourse: Perspectives for Language Teaching. Londres: Longman.

Mey, J. L. Whose Language? A Study of Pragmatics. Bélgica: John Benjamins, 1985. 
Miller, J. H. 1992. Translation as the double production of texts. In: C. Kramsch e S. McConnell-Ginet (Orgs.) Text and Context: Crossdisciplinary Perspectives on Language Studies. Lexington, MA: D.C. Heath. Murphy, B. 1988. Teaching translation and teaching through translation. In: MET 15/4: 12-15.

Phillipson, R. 1992. Linguistic Imperialism. Oxford: Oxford University Press. Poulantzas, N. 1973. Poder Político e Classes Sociais do Estado Capitalista. Londres: NLB.

Reuter, Y. 1996. Éléments de réflexion sur la place et les fonctions de la littérature dans la didactique du français à l'école primaire. In: Repères, 13: 7-25.

Revuz, C. 1998. A língua estrangeira entre o desejo de um outro lugar e o risco do exílio. Trad. S. Serrani-Infante. In: I. Signorini (org.) Lingua (gem) e Identidade. Campinas: Mercado de Letras: 213-230.

RIvière, C. 1990. Culture. In : Encyclopédie Philosophique Universelle II, Les Notions Philosophiques, vol.2, Paris: Presses Universitaires de France: 529-532.

RockHILL, K. 1993. Gender, language and the politics of literacy. In: B. Street (Org.), Cross-Cultural Approaches to Literacy. Cambridge: Cambridge University Press: 156-175.

SchaËffer, A. M. de M. 2000. Reflexões sobre o Papel da Tradução (mental) no Desenvolvimento da Leitura em Língua Estrangeira. Dissertação. Campinas: Unicamp, IEL.

Sparshott, F.E. 1978. On the possibility of saying what literature is. In: P. Hernadi (org.) What is Literature? Indiana: Indiana University Press: 3-15.

Street, B. 1984. Literacy in Theory and Practice. Cambridge: Cambridge University Press.

Solomon, R.C. 1986. Literacy and the education of the emotions. In: S. de Castell, A. Duke e K. Egan (Orgs.) Literacy, Society and Schooling. Cambridge: Cambridge University Press: 37-60.

Steiner, G. 1978. Après Babel: Une Poétique du Dire et de la Traduction. Trad. L. Lotringer. Paris : Edition Albin Michel.

Todorov, T. 1979. As Estruturas Narrativas. Trad. Leyla Perrone Moisés. São Paulo: Perspectiva.

Tomlinson, B. Openings. 1986. Londres: Lingual House.

Usher, R e Edwards, R. 1994. Postmodernism and Education. Nova York: Routledge. 
Valdes, J. M. 1986. Culture in literature. In: J. M. Valdes (Org.) Culture Bound. Cambridge: Cambridge University Press: 137-147.

VInCENT, L. 1999. La lecture de textes littéreires et l'anthropologie de la communication au service de la compétence culturelle. In: Zielsprache Französisch, 4: 147-155.

Visuvalingam, E. 2001. Apprendre par la littérature: pour une didactique du texte littéreire en FLE. In Dialogues et Cultures, 45: 312-319.

Weinrich, H. 1985. Petite xénophobie des langues étrangères. In: Communication, 43: 192-193.

Wellek, R. 1978. What is literature? In: P. Hernadi (org.) What Is Literature? Indiana: Indiana University Press: 16-23.

WILKINS, D. A. 1994. Second and foreing language teaching. In: R. E. Asher (ed.) The Encyclopedia of Language and Linguistics. Oxford: Pergamon Press: 3715.

Wilmart, F. 2002. Pour un enseignement plus objectif de la traduction de texts dits culturels ou littéraires. In: Traduire, 192: 59-74. 